\title{
Kinetic Control Over CdS Nanocrystal Nucleation Using a Library of Thiocarbonates, Thiocarbamates, and Thioureas
}

\author{
Leslie S. Hamachi, Ilan Jen-La Plante, Aidan C. Coryell, Jonathan De Roo, Jonathan S. \\ Owen* \\ tDepartment of Chemistry, Columbia University, New York, New York 10027, United States \\ KEYWORDS. quantum dot, precursor conversion, nanocrystal, size dependent extinction coefficient, \\ nucleation and growth
}

\begin{abstract}
We report a family of substituted thiocarbonates, thiocarbamates, and thioureas and their reaction with cadmium oleate at $180-240{ }^{\circ} \mathrm{C}$ to form zincblende CdS nanocrystals $(d=2.2-5.9 \mathrm{~nm})$. To monitor the kinetics of CdS formation with UV-vis spectroscopy, the size dependence of the extinction coefficient for $\lambda_{\max }\left(1 \mathrm{~S}_{\mathrm{e}}-1 \mathrm{~S}_{1 / 2 \mathrm{~h}}\right)$ is determined. The precursor conversion kinetics span five orders of magnitude depending on the precursor structure $\left(2^{\circ}\right.$-thioureas $>3^{\circ}$-thioureas $\geq 2$-thiocarbamates $>2$-thiocarbonates $>$ 4 -thioureas $\geq 3$-thiocarbamates). The concentration of nanocrystals formed by the nucleation reaction increases with increasing precursor conversion reactivity, allowing the final size to be controlled by the precursor structure. ' $\mathrm{H}$ NMR spectroscopy is used to monitor the reaction of di-p-tolyl thiocarbonate and cadmium oleate where di- $p$-tolyl carbonate and oleic anhydride coproducts can be identified. These coproducts further decompose into $p$-tolyl oleate and $p$-cresol. The spectral features of CdS nanocrystals produced from thiocarbonates are exceptionally narrow (95-161 meV FWHM) compared to those made from thioureas (137-174 meV FWHM) under otherwise identical conditions, indicating that particular precursors nucleate narrower size distributions than others.
\end{abstract}

\section{INTRODUCTION}

Mechanistic studies have shown that the nucleation and growth of metal chalcogenide nanocrystals are often limited by the kinetics of precursor conversion. ${ }^{1}$ The conversion reaction thereby controls the flow of metal chalcogenide monomers into the medium where they supersaturate, nucleate, and grow into nanocrystals. ${ }^{2}$ In this mechanistic scenario, controlling the kinetics of precursor conversion allows precise and predictable control over the nanocrystal size while optimizing the size dispersity, yield, and reaction temperature. This has inspired many precursor molecule classes such as substituted thio/selenoureas, silyl/germanyl phosphines and arsines, phosphine chalcogenides, and dichalchogenides that provide control over II$\mathrm{VI}^{1,3-6}, \mathrm{IV}-\left.\mathrm{VI}\right|^{3-4,7}$ and III-V8-10 nanocrystal syntheses.

CdS nanocrystals have been synthesized from bis(trimethylsilyl)sulfide, ${ }^{11}$ phosphine sulfides, ${ }^{12}$ or sulfur dissolved in octadecene. ${ }^{13-14}$ These precursors provide limited tunability and/or produce un- wanted side products. In our attempts to synthesize CdS nanocrystals from thioureas we found that $N, N^{\prime}$-disubstituted and most $N, N, N$ '-trisubstituted thioureas proved too reactive toward cadmium oleate at the relatively high temperatures needed for crystal growth. On the other hand, the reactivity of most $N, N, N^{\prime}, N^{\prime}$-tetrasubstituted thioureas is too sluggish at temperatures where cadmium carboxylate is stable. In order to circumvent this issue, we sought precursors with intermediate reactivity. For this purpose we investigated the synthesis of CdS from substituted thiocarbonates and thiocarbamates. Among these, and suitably reactive thioureas, the thiocarbonate derivatives produce the narrowest size distributions, suggesting that precursors can impact both the crystallization mechanism and the solute supply kinetics.

\section{RESULTS AND DISCUSSION}

A variety of $0, O^{\prime}$-disubsituted thiocarbonates are obtained in good yields form $O$-arylchlorothionoformates or thiocarbonyldiimidazole 
(Scheme 1 and Table 1). ${ }^{15}$ While the reaction of phenols and chlorothionoformate proceeds to completion after $10 \mathrm{~min}$ at $80{ }^{\circ} \mathrm{C}$, the analogous reaction with thiocarbonyldiimidazole requires 16 hours in refluxing acetonitrile and trifluoroacetic acid (10 mol \%) to complete the second substitution. Similarly, secondary amines react with thiocarbonyldiimidazole to provide $N, N, N^{\prime}, N^{\prime}$-tetrasubstituted thioureas. Again the first imidazole substitution proceeds rapidly while the second required stirring overnight, although the reaction could be conducted at room temperature because of the greater nucleophilicity of amines. Following recrystallization from methanol, acetonitrile, or dichloromethane, analytically pure, white, microcyrstalline products are obtained in 44-76\% isolated yields.

Scheme 1. Synthesis of thiocarbonate, thiocarbamate and $N, N, N^{\prime}, N^{\prime}$-tetrasubstituted thiourea precursors.

$$
\begin{aligned}
& \underset{\mathrm{ArO}}{\stackrel{\mathrm{S}}{\mathrm{L}}} \mathrm{Cl}+\mathrm{ROH} \underset{80{ }^{\circ} \mathrm{C}, 10 \mathrm{~min} .}{\stackrel{\mathrm{C}_{6} \mathrm{H}_{6}, \text { pyridine }}{\longrightarrow}} \stackrel{\mathrm{ArO}_{\mathrm{OR}}}{\stackrel{\mathrm{S}}{\mathrm{L}}} \\
& \underset{\mathrm{ArO}}{\stackrel{\mathrm{S}}{\mathrm{L}}} \mathrm{Cl}+2 \mathrm{H}-\mathrm{NR}_{2} \stackrel{\mathrm{CH}_{2} \mathrm{Cl}_{2}}{\longrightarrow} \stackrel{\mathrm{S}}{\stackrel{\mathrm{C}}{\longrightarrow}} \mathrm{NR}_{2}
\end{aligned}
$$

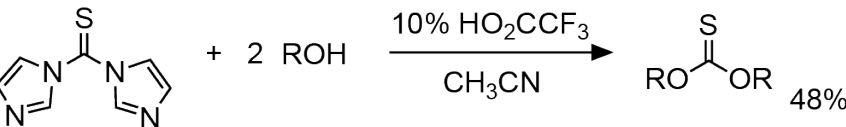

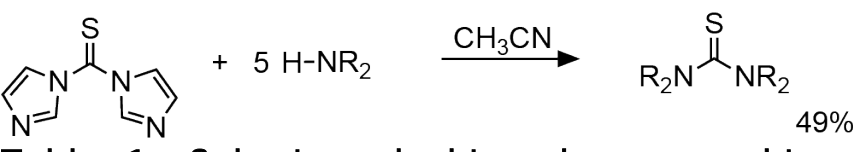

Table 1. Substituted thiocarbonates, thio-

\begin{tabular}{|c|c|c|c|}
\hline & $X_{1}$ & $X_{2}$ & $\begin{array}{l}\text { Precursor } \\
\text { Yield }\end{array}$ \\
\hline $\begin{array}{l}1 \\
\mathrm{a}\end{array}$ & O-4-MeO-Ph & O-4-MeO-Ph & $48 \%$ \\
\hline $\begin{array}{l}1 \\
b\end{array}$ & O-4-Me-Ph & O-4-MeO-Ph & $67 \%$ \\
\hline $\begin{array}{l}1 \\
c\end{array}$ & O-4-Me-Ph & O-4-Me-Ph & $76 \%$ \\
\hline $\begin{array}{l}1 \\
d\end{array}$ & O-4-Me-Ph & O-Ph & $66 \%$ \\
\hline $\begin{array}{l}1 \\
\mathrm{e}\end{array}$ & O-Ph & $\mathrm{O}-\mathrm{Ph}$ & $67 \%$ \\
\hline $1 \mathrm{f}$ & O-4-Me-Ph & O-4-Cl-Ph & $68 \%$ \\
\hline $\begin{array}{l}1 \\
g\end{array}$ & O-4-Me-Ph & $\mathrm{O}-4-\mathrm{CF}_{3}-\mathrm{Ph}$ & $61 \%$ \\
\hline 1 & O-4-Me-Ph & O-Cy & $62 \%$ \\
\hline
\end{tabular}
carbamates, and thioureas used in this study.

\begin{tabular}{|l|l|l|l|}
\hline $\mathrm{h}$ & & & \\
\hline $1 \mathrm{i}$ & O-Ph & O-4-Cl-Ph & $60 \%$ \\
\hline $1 \mathrm{j}$ & O-4-Me-Ph & $\begin{array}{l}\text { O-2,6-diMe- } \\
\mathrm{Ph}\end{array}$ & $44 \%$ \\
\hline 2 & O-4-Me-Ph & $\mathrm{N}-\mathrm{H}(4-\mathrm{Me}-\mathrm{Ph})$ & $71 \%$ \\
\hline 3 & O-4-Me-Ph & $\mathrm{N}-\left(\mathrm{CH}_{3}\right) \mathrm{Ph}$ & $74 \%$ \\
\hline $\begin{array}{l}4 \\
\text { * }\end{array}$ & $\begin{array}{l}\mathrm{N}-\mathrm{H}(4-\mathrm{Me}- \\
\mathrm{Ph})\end{array}$ & $\mathrm{N}-\mathrm{H}(4-\mathrm{Me}-\mathrm{Ph})$ & a \\
\hline $\begin{array}{l}5 \\
\text { a }\end{array}$ & $\mathrm{N}-\mathrm{HPh}$ & $\mathrm{N}-(\mathrm{n}-\mathrm{Bu})_{2}$ & Ref. 3 \\
\hline $\begin{array}{l}5 \\
\text { b }\end{array}$ & $\mathrm{N}-\mathrm{HPh}$ & $\mathrm{N}-\left(\mathrm{CH}_{3}\right) \mathrm{Ph}$ & $92 \%$ \\
\hline $\begin{array}{l}6 \\
\text { a }\end{array}$ & $\mathrm{N}-\left(\mathrm{CH}_{3}\right)_{2}$ & $\mathrm{~N}-\left(\mathrm{CH}_{3}\right)_{2}$ & a \\
\hline $\begin{array}{l}6 \\
\text { b }\end{array}$ & $\mathrm{N}-($ pyrr $)$ & $\mathrm{N}-($ pyrr $)$ & $49 \%$ \\
\hline
\end{tabular}

a Commercially available; * mixing limited at $240^{\circ} \mathrm{C}$, so run at $180^{\circ} \mathrm{C}$.

CdS nanocrystals were synthesized by injecting a solution of the precursors shown in Table 1 (1a$6 \mathrm{~b})$ into 1.2-1.5 equiv. of cadmium oleate dissolved in octadecene $(10 \mathrm{mM})$ at $180-240{ }^{\circ} \mathrm{C}$ (Scheme 2). Oleic acid (2.4 equiv.) is added to improve the thermal stability of the cadmium oleate precursor, which occasionally decomposed to a turbid mixture when stirred in octadecene at 240 ${ }^{\circ} \mathrm{C}$ on its own. Zincblende nanocrystals with a wide range of final diameters $(d=2.2-5.9 \mathrm{~nm})$ are obtained depending on the sulfur precursor used (Figures 1 and S1-S4). Reaction temperatures as low as $180{ }^{\circ} \mathrm{C}$ could be used without significantly broadening the nanocrystals optical features.

A Cd:S stoichiometry greater than 1:1 provides cadmium oleate ligands that passivate the nanocrystal surface and maintain the colloidal stability. Reactions that produce smaller final sizes required a greater amount of cadmium oleate ( 1.5 equiv.) to prevent loss of the narrow optical features toward the end of the reaction (Figure S5). Similar broadening is observed in the synthesis of small diameter $\mathrm{PbS}$ nanocrystals if lead oleate is not present in sufficient excess. Depletion of metal oleate by the conversion reaction is thought to reduce the ligand coverage and destabilize the dispersion, particularly at long reaction times. The greater surface area to volume ratio and metal enrichment of small nanocrystals could magnify the effect. Following the synthesis, the nanocrystals are carefully purified by precipitation and centrifugation until the ${ }^{1} \mathrm{H}$ NMR spectrum only displays the broad resonances of surface bound cadmium oleate ligands. The oleate 
coverages range from $0.9-2.0 \mathrm{Cd}$ (oleate) ${ }_{2} \mathrm{~nm}^{-2}$ (Figure S4).

To gain insight into the precursor conversion mechanism, ${ }^{1} \mathrm{H}$ NMR spectroscopy was used to monitor the reaction coproducts. For example, $N, N, N^{\prime}, N^{\prime}$-tetramethylthiourea (6a) $\left(\delta\left(\mathrm{CH}_{3}\right)=3.1\right.$ ppm) reacts with cadmium oleate to produce $N, N, N$,'N',-tetramethylurea $\left(\delta\left(\mathrm{CH}_{3}\right)=2.8 \mathrm{ppm}\right)$ and oleic anhydride $\left(\delta\left(\alpha-\mathrm{CH}_{2}\right)=2.47 \mathrm{ppm}\right)$ (Figure S6). Analogous $0, O^{\prime}$-disubstituted carbonate and oleic anhydride coproducts form from thiocarbonates $1 \mathrm{c}$ and $1 \mathrm{e}$. In both cases, these coproducts go on to other species described below.

Scheme 2. Standard reaction conditions for the synthesis of CdS Nanocrystals from cadmium oleate and a sulfur precursor listed in Table 1.

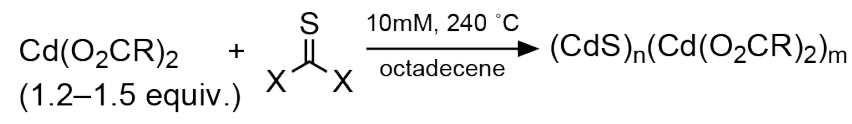

$\mathrm{X}=\mathrm{OR}, \mathrm{NR}_{2}$

$\mathrm{O}_{2} \mathrm{CR}=$ oleate

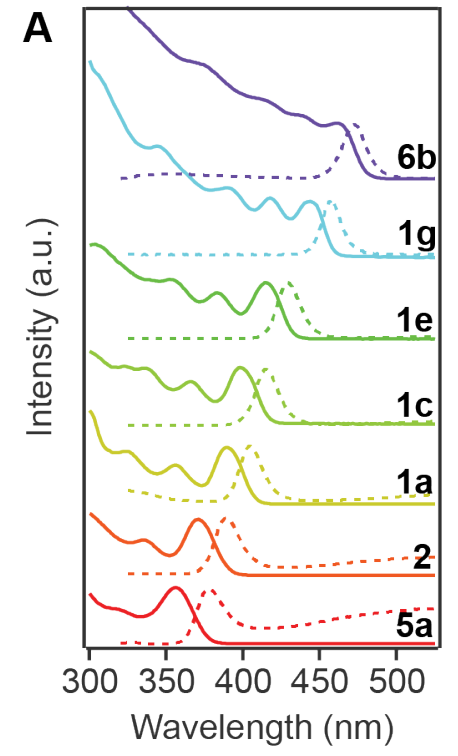

$d=2.5-5.7 \mathrm{~nm}$
$\lambda\left(1 \mathrm{~S}_{\mathrm{e}}-1 \mathrm{~S}_{\mathrm{h}}\right)=355-460 \mathrm{~nm}$

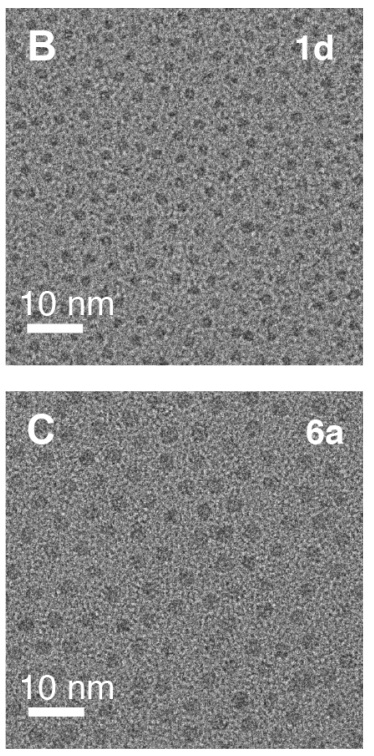

Figure 1. (A) Absorption and fluorescence spectra from CdS nanocrystals spanning a full range of sizes can be prepared by selecting the appropriate precursor. TEM of nanocrystals prepared from $1 \mathrm{~d}(\mathrm{~B})$ and $6 \mathrm{a}$ (C).

Scheme 3. Coproducts of precursor conversion reaction. ${ }^{a}$
A

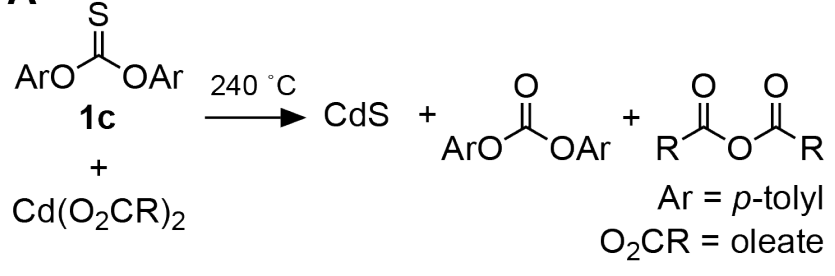

B

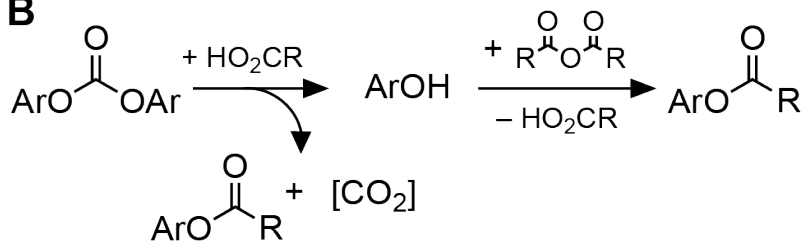

a $p$-tolylcarbonate and oleic anhydride coproducts undergo further conversion to $p$-tolyl oleate and carbon dioxide via $p$-cresol. The formation of $p$-cresol suggests the process is catalyzed by oleic acid.

In the case of $1 \mathrm{c}, p$-tolyl oleate and $p$-cresol build in concentration as the initially formed di- $p$-tolyl carbonate and oleic anhydride disappear (Figures 2 and S7-S8). We infer from this observation that the carbonate coproduct reacts with oleic acid and/or moisture to form $p$-tolyl oleate and/or $p$-cresol (Scheme 3). This reaction was also observed in a control experiment in the absence of nanocrystals, however, the rate is too slow to explain the results, suggesting that cadmium oleate activates the di- $p$ tolyl carbonate toward attack (Figures S10-S11). Indeed, precedent for Lewis acid catalysis of decarboxylative esterification of carboxylic acids with dicarbonates has been established. ${ }^{16}$

As the reaction proceeds and the di- $p$-tolyl carbonate disappears, $p$-tolyl oleate continues to build in concentration. At the same time, $p$-cresol persists in the product mixture, suggesting that hydrolysis of oleic anhydride and/or the di-p-tolyl carbonate by adventitious water also plays a role in the coproduct evolution. Oleic acid anhydride, on the other hand, is only present in low concentration and at early times, presumably because its reaction with $p$-cresol and moisture is rapid. This was confirmed by a control experiment, which is indeed rapid even in the absence of Lewis acid catalysis (Figures S12-S13). These findings are consistent with the mechanistic hypothesis in Scheme 3. An analogous mechanism may explain the reaction of the $N, N, N^{\prime}, N^{\prime}$-tetramethyl thiourea. 


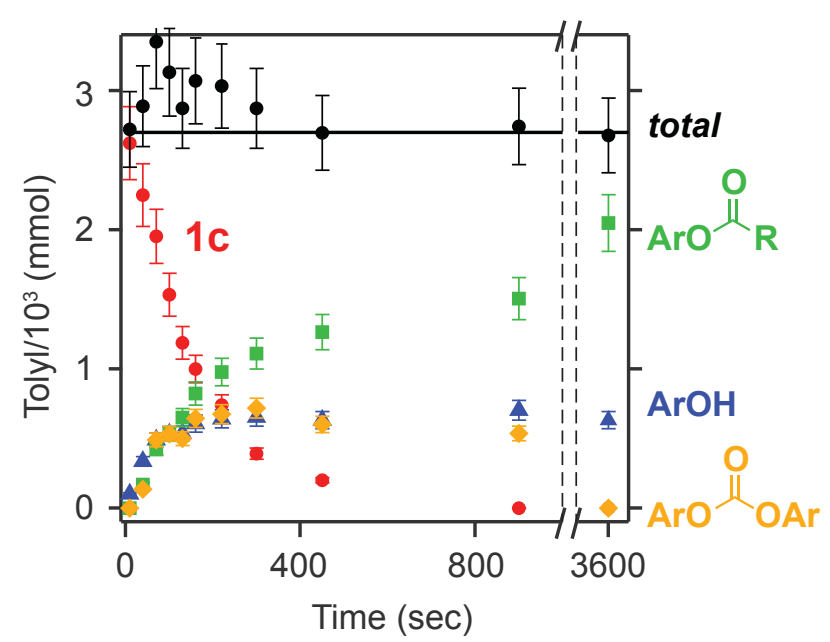

Figure 2. Reaction coproducts of 1c with cadmium oleate are observed via ${ }^{1} \mathrm{H}$ NMR and evolve over time to yield $p$-tolyl oleate and $p$-cresol.

Precursor conversion kinetics were also monitored using UV-vis absorption spectroscopy. The concentration of $\mathrm{CdS}$ can be measured from the intensity of the $1 \mathrm{~S}_{\mathrm{e}}-1 \mathrm{~S}_{1 / 2 \mathrm{~h}}$ transition using a published size dependent extinction coefficient. ${ }^{17}$ However, error in this extinction coefficient, particularly at small sizes, leads to erroneous yields (as much as twice the theoretical yield) (Figure S14). Similar issues with the size dependent extinction coefficient of CdSe nanocrystals published in that same report have been described. ${ }^{18}$

To estimate the extinction coefficient of the $1 \mathrm{~S}_{\mathrm{e}}-$ $1 \mathrm{~S}_{1 / 2 \mathrm{~h}}$ transition, CdS nanocrystals were synthesized from a variety of tri and tetrasubstituted thioureas (5a-6b). We verified, a near quantitative yield of CdS from $6 \mathrm{a}$ by the complete disappearance of the thiourea and by measuring the empirical formula and mass of the CdS nanocrystals (See Experimental section and Figures S4 and S9). By assuming a $100 \%$ conversion of the thiourea to CdS, the extinction coefficient of the lowest energy excitonic transition could be estimated at the end of the reaction (Figure S15). These values are compared to the previously reported size dependent extinction coefficient in Figure 3. Significant differences between the curves are visible at small nanocrystal sizes, which explains the erroneous yields obtained when using the previously reported extinction coefficient. A second order polynomial fit to our data is shown below (Eq. 1). It is worth noting that this approach does not account for differences in the size distribution of samples. Further studies on the intrinsic linewidth of a single CdS nanocrystals are required before differences in the size distribution can be used to modify the extinction coefficient.

$$
\varepsilon(D)\left[M(C d S)^{-1} \mathrm{~cm}^{-1}\right]=
$$

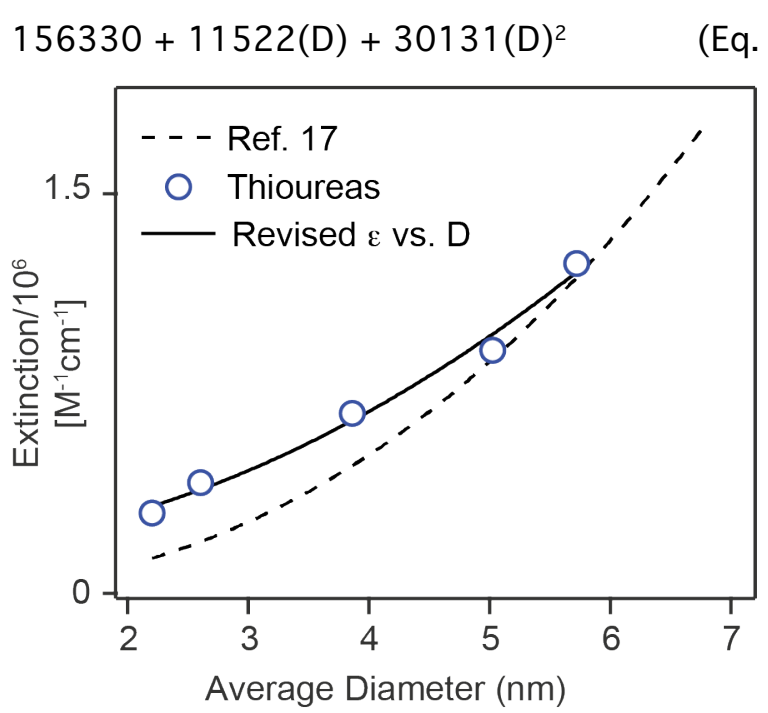

Figure 3. Experimentally determined extinction coefficients made using CdS nanocrystals produced from thioureas $5 a-6 b$.

Using our revised size dependent extinction coefficient (Equation 1), the yield of CdS from $1 \mathrm{a}-6 \mathrm{~b}$ was monitored from timed reaction aliquots (Figures S14-S16). A single exponential fit was used to extract an observed rate constant $\left(k_{\mathrm{obs}}\right)$ for each precursor in order to understand the effect of the substitution pattern on the reactivity. However, unlike the kinetics of forming $\mathrm{PbS}$ and $\mathrm{PbSe}$ nanocrystals from thio- and selenoureas, ${ }^{3-4}$ in most cases, the kinetics observed here are multiexponential and the $k_{\text {obs }}$ represents an average of more complex behavior. Nonetheless, this approach allows the precursor reactivities to be ordered in a semiquantitative fashion. The $k_{\mathrm{obs}}$ extracted from the UV-Vis kinetics for each precursor is plotted in Figure 4 below, illustrating the wide range of conversion reactivity.

Among disubstituted precursors, the conversion reactivity decreases from thiourea $>$ thiocarbamate $>$ thiocarbonate (Figure 4, S17). While cadmium oleate and $N, N$ '-disubstituted thioureas react completely in a minute or less, thiocarbonate precursors convert slowly over the course of minutes to hours. Increasing the number of substituents slows the reactivity of both the thiocarbamate and thiourea classes. For example, $N, N$ '-disubstituted thioureas are faster than $N, N, N^{\prime}$-trisubstituted thioureas by an order of magnitude, which are faster than $N, N, N^{\prime}, N^{\prime}$-tetrasubstituted thioureas by an additional two orders of magnitude. Thus, much like in previous studies on the reaction with lead oleate, modifying the number of $\mathrm{N}-\mathrm{H}$ bonds has a large effect on the reactivity. 
Among thiocarbonate precursors, those with electron donating substituents display faster conversion kinetics. However, ortho-substituted aryl groups inhibit the conversion step, making the 2,6xylyl derivative $(1 \mathrm{j})$ much more sluggish than the related $p$-tolyl derivative (1c). Both observations are consistent with a conversion reaction mechanism where pre-equilibrium binding of the thiocarbonate to cadmium oleate precedes the cleavage of the $\mathrm{S}=\mathrm{C}$ bond by attack at the thione carbon. An analogous mechanism leads to the cleavage of phosphine chalcogenides coordinated to cadmium oleate. ${ }^{19}$

A
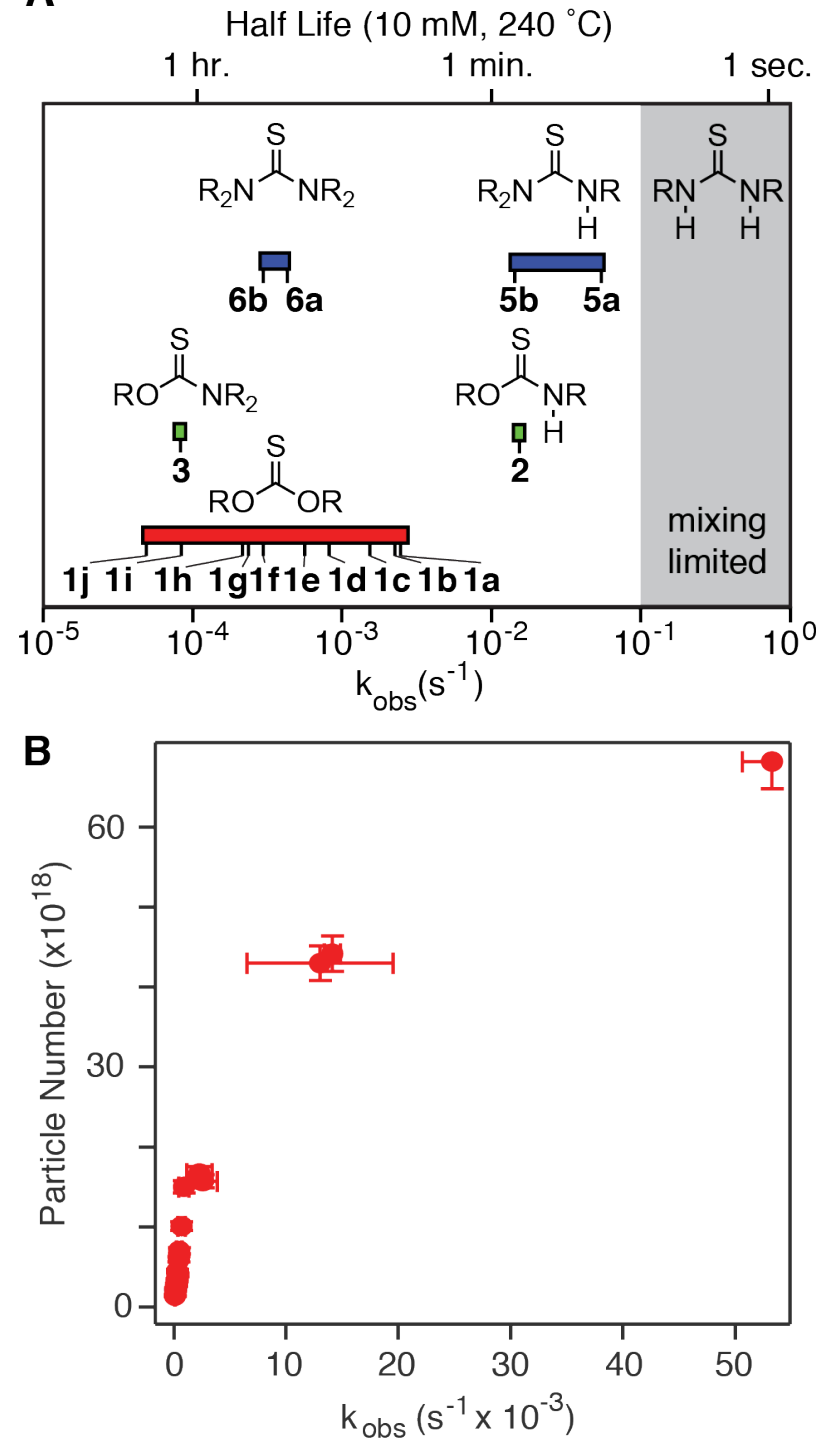

Figure 4. A) Ranges of precursor reactivity with cadmium oleate under standardized reaction conditions. B) Particle number vs. precursor conversion rate constant.

Previous studies of $\mathrm{CdSe}, \mathrm{PbS}$, and $\mathrm{PbSe}$ have shown a correlation between the precursor conversion reactivity and the number of nanocrystals; faster reactions produce a higher concentration of smaller nanocrystals. ${ }^{1,3-4,20-22}$ A similar trend is observed here, where less reactive precursors produce larger CdS nanocrystals (Figure 4). However, precursors used in this study produce $53-89 \% \pm$ $7 \%$ yields of CdS depending on the substituents, which also influences the final size. Thiocarbonates with electron deficient substituents $(1 \mathrm{~h}-1 \mathrm{j})$ produced the lowest yields (as low as $53 \%$ ), as did a slow reacting thiocarbamate (3) (62\%). Other thiocarbamates proved even more problematic and are not described here. The low yield is likely the result of Miyazaki-Newman-Kwart and Schönberg rearrangements for thiocarbamates and thiocarbonates, respectively, that compete with the conversion reaction (Scheme 4). ${ }^{23-26}$ These rearrangements are accelerated by electron withdrawing substituents and are known to be faster for thiocarbamates than thiocarbonates. We tentatively conclude that these rearrangements explain the reduced the yields described above, however we were unable to determine the fate of the rearranged product in final reaction mixtures. Two observations support our conclusion: (1) heating di-p-tolyl thiocarbonate and oleic acid to the temperature used to synthesize CdS $\left(240{ }^{\circ} \mathrm{C}\right)$ slowly produces the rearrangement product, $O, S$ - $p$-tolyl thiolcarbonate (Figure S18), (2) an independently synthesized $O, S^{\prime}$-disubstituted thiolcarbonate proved unreactive toward cadmium oleate after 6 hours at $240{ }^{\circ} \mathrm{C}$ (Figure S19), confirming that the formation of the rearrangement product can limit the yield of CdS. Regardless, in cases were the yield is lower than $100 \%$, we showed that additional precursor can be added to drive the reaction forward without compromising the size distribution (Figure S20).

Scheme 4. Isomerization of thiocarbonates and thiocarbamates via a polar transition structure. ${ }^{23}$

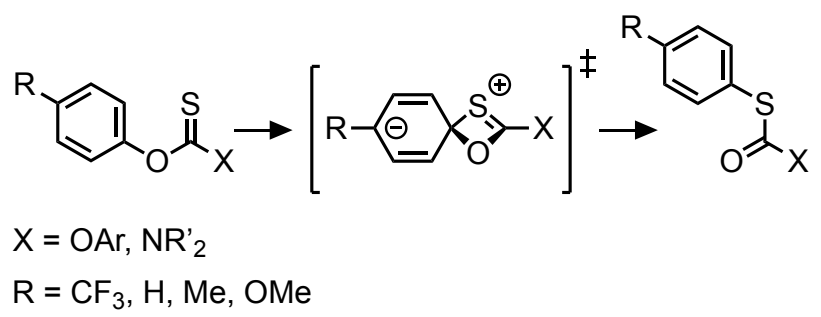

Interestingly, in most cases, nanocrystals prepared from thiocarbonates display optical features that are narrower than those prepared from thiourea or thiocarbamate precursors (Figure 5). The spectra of similarly sized nanocrystals prepared from thiocarbonates and thioureas are compared in Figure $5 \mathrm{~A}$, clearly showing the narrower features of the thiocarbonate sample. Both samples possess 
very narrow size distributions that are not easily distinguished using transmission electron microscopy (Figure S21). By plotting the FWHM of the nanocrystal photoluminescence versus the peak energy a decreasing linewidth with increasing size is visible. Recent studies of $\mathrm{PbS}, \mathrm{PbSe}$, and $\mathrm{CdSe}$ have shown that size dependent broadening from exciton phonon coupling, exciton fine structure, and surface chemistry account for the majority of the linewidth in high quality samples. ${ }^{27-31}$ We conclude that for a given size, nanocrystals prepared from thiocarbonates have significantly narrower features than those derived from thioureas and thiocarbamates.
A

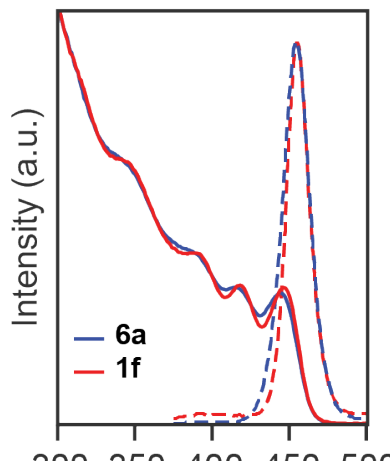

300350400450500

Wavelength $(\mathrm{nm})$
B

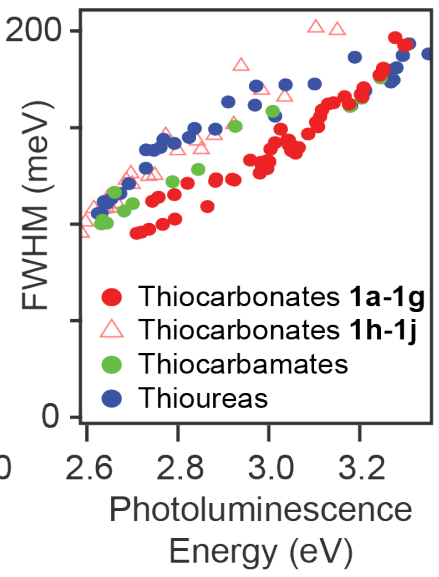

Figure 5. a) Comparison of UV-vis and fluorescence spectra of CdS nanocrystals synthesized from thiocarbonate $1 \mathrm{f}$ vs. thiourea $6 \mathrm{a}$. b) FWHM vs. energy of photoluminescence from aliquots of $\mathrm{CdS}$ syntheses using thioureas, thiocarbonates, and thiocarbamates.

With the exception of thiocarbonates $1 \mathrm{~h}-1 \mathrm{j}$, the most narrow distributions across the range are created by the thiocarbonate precursors. The especially narrow distributions are present throughout the growth indicating that they are a consequence of differences in the nucleation process. ${ }^{32}$ Moreover, we found that the proposed rearrangement coproducts can negatively influence the size distribution. For example, adding $O, S$-di- $p$-tolyl thiocarbamate to a synthesis conducted with (6a) resulted in substantially more polydisperse nanocrystals with weak photoluminescence (Figure S23). This may help explain why $1 \mathrm{~h}-1 \mathrm{j}$, compounds which presumably form significant amounts of these rearrangement coproducts, produce broader size distributions than the other thiocarbonate precursors.

In principle, the precursor structure can be used to tune the solute supply kinetics and the final nanocrystal size, without simultaneously influencing factors such as the surface structure, surface ten- sion, or monomer solubility. In this way, the precursor conversion reaction can be described as 'orthogonal' to the crystal nucleation and growth reactions. Other strategies to tune the nanocrystal size, such as adjusting the reaction temperature or the surfactants, influence both the precursor conversion kinetics and the nucleation and growth steps. Thus, orthogonal precursor reactivity provides greater flexibility to improve the final nanocrystal product and to probe the mechanism of nanocrystal formation. The especially narrow size distributions produced by the thiocarbonate derivatives may benefit from this orthogonality. On the other hand, precursors that produce undesirable byproducts or that coordinate the cadmium oleate, CdS monomers, or growing nanocrystal surface, may negatively (or positively) influence the nucleation phase. To understand these features and design nanocrystal better synthesis reagents, a deeper understanding of precursor reactivity is needed.

\section{CONCLUSIONS}

We introduced two new classes of sulfide precursors: thiocarbonates and thiocarbamates whose conversion kinetics to CdS nanocrystals supplement gaps in the existing thiourea library. The expanded library's reactivity with cadmium oleate now encompasses five orders of magnitude. Most excitingly, we note that thiocarbonates produce nanocrystals with narrower optical features than other precursor compounds with similar conversion kinetics, suggesting that precursor structure controls sample polydispersity in addition to conversion rate.

\section{EXPERIMENTAL METHODS}

General Considerations. All manipulations were performed in air unless otherwise indicated. Toluene (99.5\%), methyl acetate (99\%), benzene (99.8\%), hexanes (98.5\%), methanol (99.8\%), ethanol $(\geq 99.8 \%)$, dichloromethane $(\geq 99.5 \%)$, chloroform ( $\geq 99.8 \%)$, acetone $(\geq 99.8 \%)$, acetonitrile $(99.5 \%)$, cadmium nitrate tetrahydrate (98\%), sodium hydroxide $(\geq 98 \%)$, sodium bicarbonate ( $\geq 99.7 \%)$, hydrochloric acid (37\%), oleoyl chloride $(\geq 89 \%)$, sodium chloride $(\geq 99 \%)$, sodium sulfate ( $\geq 99 \%)$, tetramethylthiourea (98\%) (3), phenyl isothiocyanate (98\%), $p$-tolyl isothiocyanate (97\%), triethylamine $(\geq 99.5 \%)$, dibutylamine (99.5\%), p-toluidine (99.6\%), O-Phenyl chlorothionoformate (99\%), 4-methoxyphenol (99\%), 4-(Trifluoromethyl)phenol (97\%), phenol ( $\geq 96.0 \%)$, p-cresol ( $\geq 99 \%)$, cyclohexanol (99\%), pyrrolidine (99\%), and dimethyl terepthalate $(\geq 99.0 \%)$ were obtained from Sigma Aldrich and 
used without further purification. 4-Chlorophenol (99\%) was obtained from Alfa Aesar and used without further purification. Pentafluorophenol $(\geq 99 \%)$ was obtained from Oakwood Products and used without further purification. Oleic anhydride was obtained from TCl Chemicals and used without further purification. Oleic acid (99\%), O-( $p$-tolyl) chlorothionoformate $(97 \%$ or $\geq 97 \%)$, and 1,1 'thiocarbonyldiimidazole $(\geq 95.0 \%$ or $90 \%)$ were obtained from either Sigma Aldrich or Alfa Aesar and used without further purification. Diphenyl ether (99\%), pyridine (98\%), 1-octadecene (90\%), hexadecane $(99 \%)$, and tetraethylene glycol dimethyl ether ("tetraglyme" $\geq 99 \%$ ), aniline (99\%), and $\mathrm{N}$-methyl aniline (98\%) were obtained from Sigma Aldrich, stirred with calcium hydride overnight, and distilled prior to use. Chloroform- $d$ (99.8\%), benzene- $d_{6}(99.5 \%)$, and methylene chloride- $d_{2}(99.8 \%)$ were obtained from Cambridge Isotopes and used without further purification.

UV-Vis spectra were obtained using a PerkinElmer Lambda 950 spectrophotometer equipped with deuterium and halogen lamps. Photoluminescence measurements were performed using a Fluoromax 4 from Horiba Scientific, and photoluminescence quantum yields were determined using a quanta-phi integrating sphere accessory according to a previously described procedure. ${ }^{33}$ Powder X-ray diffraction (XRD) was measured on a PANalytical X'Pert Powder X-ray diffractometer. Transmission electron microscopy (TEM) was performed on a FEI T12 BioTWIN. Scanning transmission electron microscopy (STEM) was performed on a FEI Talos F200X.

Synthesis of cadmium oleate $\left(\mathrm{Cd}(\text { oleate })_{2}\right)$. Cadmium oleate was synthesized on a $60 \mathrm{mmol}$ scale according to Yang et al. ${ }^{34}$

0,0 '-bis(4-methoxyphenyl) thiocarbonate (1 a). 4-methoxyphenol (8.94 g, $72 \mathrm{mmol}), 1,1$ 'thiocarbonyldiimidazole $(7.06 \mathrm{~g}, 39.6 \mathrm{mmol})$, acetonitrile $(144 \mathrm{~mL})$, and a stir bar are added to a Teflon sealable schlenk flask. Trifluoroacetic acid $(0.41 \mathrm{~g}, 0.275 \mathrm{~mL}, 3.6 \mathrm{mmol})$ is added dropwise, the flask is sealed, heated to $70{ }^{\circ} \mathrm{C}$ in an oil bath, and left stirring overnight. The reaction is cooled and the volatiles removed under vacuum. The residue is dissolved in dichloromethane, and washed with $\mathrm{HCl}(1 \mathrm{M}), \mathrm{NaOH}(1 \mathrm{M})$, saturated brine, and dried over $\mathrm{Na}_{2} \mathrm{SO}_{4}$. The volatiles are removed under vacuum and the resulting solid is recrystallized from acetonitrile to yield white needles. A second crop of crystals was grown from concentrating the filtrate and crystallizing at $-20{ }^{\circ} \mathrm{C}$. Yield $5.50 \mathrm{~g}(48 \%) .{ }^{1} \mathrm{H}$ $\operatorname{NMR}\left(400 \mathrm{MHz}, \mathrm{CDCl}_{3}\right): \delta=3.82(\mathrm{~s}, 6 \mathrm{H}), 6.92-6.98$ $(\mathrm{m}, 4 \mathrm{H}), 7.10-7.16(\mathrm{~m}, 4 \mathrm{H}) ;{ }^{13} \mathrm{C}\left\{{ }^{1} \mathrm{H}\right\} \quad(100 \mathrm{MHz}$, $\left.\mathrm{CDCl}_{3}\right): \delta=55.72,114.68,122.70,147.36$, 158.0, 196.13; Anal. Calcd for $\mathrm{C}_{15} \mathrm{H}_{14} \mathrm{O}_{4} \mathrm{~S}: \mathrm{C}$, 62.05; $\mathrm{H}$, 4.86. Found: $\mathrm{C}, 61.29$; $\mathrm{H}, 4.16$. MS (FAB) $\mathrm{m} / \mathrm{z}$ Calcd for $\left[\mathrm{C}_{15} \mathrm{H}_{14} \mathrm{O}_{4} \mathrm{~S}+\mathrm{H}^{+}\right]$: 291.07. Found: 291.07.

Thiocarbonates $(1 \mathrm{~b}-1 \mathrm{j})$. Thiocarbonates were synthesized using a slightly modified literature procedure ${ }^{15}$ that is described for $1 \mathrm{~b}$ below. It is important that pyridine is used instead of triethylamine or an undesirable side reaction results. ${ }^{35}$

$O$-(4-methoxyphenyl)-O'-( $p$-tolyl) thiocarbonate (1b). A solution of 4-methoxyphenol $(0.621 \mathrm{~g}, 5 \mathrm{mmol})$ in $10 \mathrm{~mL}$ of benzene is added to a solution of $\mathrm{O}$-( $p$-tolyl) chlorothionoformate $(0.933 \mathrm{~g}, 5 \mathrm{mmol})$ in $10 \mathrm{~mL}$ benzene. To this mixture pyridine $(0.56 \mathrm{~mL}, 7 \mathrm{mmol})$ is added dropwise. The solution turns from yellow to orange, and an orange oil separates. The mixture is heated to reflux for 10 minutes and the solution becomes a pale yellow color with a white crystalline precipitate. In a separatory funnel the benzene solution is washed with water, saturated brine, and then dried over $\mathrm{Na}_{2} \mathrm{SO}_{4}$. Removing the volatiles en vacuo yields $1.11 \mathrm{~g}$ of a white powder. Recrystallization from methanol yields $0.924 \mathrm{~g}(67 \%)$ of $1 \mathrm{~b}$ as white crystals. ' $\mathrm{H}$ NMR $\left(400 \mathrm{MHz}, \mathrm{CDCl}_{3}\right): \delta=2.42(\mathrm{~s}$, $3 \mathrm{H}), 3.86(\mathrm{~s}, 3 \mathrm{H}), 7.02-6.94(\mathrm{~m}, 2 \mathrm{H}), 7.20-7.10$ $(\mathrm{m}, 4 \mathrm{H}), 7.31-7.25(\mathrm{~m}, 2 \mathrm{H}) ;{ }^{13} \mathrm{C}\left\{{ }^{1} \mathrm{H}\right\} \quad(100 \mathrm{MHz}$, $\left.\mathrm{CDCl}_{3}\right): \delta=21.13,55.71, \quad 114.69$, 121.55, $122.70, \quad 130.30,136.69,147.38,151.66$, 158.04, 195.79; Anal. Calcd for $\mathrm{C}_{15} \mathrm{H}_{14} \mathrm{O}_{3} \mathrm{~S}$ : C, 65.67; $\mathrm{H}$, 5.14. Found: $\mathrm{C}, 65.60 ; \mathrm{H}$, 4.87. MS (ASAP) $\mathrm{m} / \mathrm{z}$ Calcd for $\left[\mathrm{C}_{15} \mathrm{H}_{14} \mathrm{O}_{3} \mathrm{~S}+\mathrm{H}^{+}\right]: 275.07$. Found: 275.07.

$0,0^{\prime}$-di-p-tolyl thiocarbonate (1c). The crude material $(1.13 \mathrm{~g})$ was recrystallized from methanol to yield $0.984 \mathrm{~g}(76 \%)$ of $1 \mathrm{c}$ as white crystals. ${ }^{1} \mathrm{H}$ NMR $\left(400 \mathrm{MHz}, \mathrm{CDCl}_{3}\right): \delta=2.38$ (s, $6 \mathrm{H})$, 7.07-7.12 (m, 4H), 7.22-7.27 (m, 4H); ${ }^{13} \mathrm{C}\left\{{ }^{1} \mathrm{H}\right\} \quad\left(100 \mathrm{MHz}, \mathrm{CDCl}_{3}\right): \delta=21.14,121.57$, 130.31, 136.71, 151.65, 195.52; Anal. Calcd for $\mathrm{C}_{15} \mathrm{H}_{14} \mathrm{O}_{2} \mathrm{~S}$ : C, 69.74; $\mathrm{H}$, 5.46. Found: $\mathrm{C}, 69.74 ; \mathrm{H}$, 5.24. MS (ASAP) $\mathrm{m} / \mathrm{z}$ Calcd for $\mathrm{C}_{15} \mathrm{H}_{14} \mathrm{O}_{2} \mathrm{~S}+\mathrm{H}^{+}$: 259.08. Found: 259.08 .

$O$-phenyl-O'-(p-tolyl) thiocarbonate $(1 \mathrm{~d})$. The crude material $(1.03 \mathrm{~g})$ was recrystallized from methanol to yield $0.802 \mathrm{~g}(66 \%)$ of $1 \mathrm{~d}$ as white crystals. ${ }^{1} \mathrm{H}$ NMR $\left(400 \mathrm{MHz}, \mathrm{CDCl}_{3}\right): \delta=2.43$ (s, $3 \mathrm{H}), 7.13-7.19(\mathrm{~m}, 2 \mathrm{H}), 7.24-7.33(\mathrm{~m}, 4 \mathrm{H}), 7.34-$ $7.40(\mathrm{~m}, 1 \mathrm{H}), 7.47-7.54(\mathrm{~m}, 2 \mathrm{H}) ;{ }^{13} \mathrm{C}\left\{{ }^{1} \mathrm{H}\right\} \quad(100$ $\left.\mathrm{MHz}, \mathrm{CDCl}_{3}\right): \delta=21.13,121.54,121.97,126.91$, $129.77, \quad 130.32, \quad 136.73, \quad 151.62,153.73$, 195.21; Anal. Calcd for $\mathrm{C}_{14} \mathrm{H}_{12} \mathrm{O}_{2} \mathrm{~S}$ : C, 68.83; H, 
4.95. Found: $\mathrm{C}, 68.61 ; \mathrm{H}, 4.65$. MS (ASAP) $\mathrm{m} / \mathrm{z}$ Calcd for $\mathrm{C}_{14} \mathrm{H}_{12} \mathrm{O}_{2} \mathrm{~S}+\mathrm{H}^{+}$]: 245.06. Found: 245.06.

$0, O^{\prime}$-di-phenyl thiocarbonate (1e). The crude material $(1.01 \mathrm{~g})$ was further purified by recrystallization from acetonitrile to yield $0.770 \mathrm{~g}$ (67\%) of $1 \mathrm{e}$ as white crystals. ${ }^{1} \mathrm{H}$ NMR $(400 \mathrm{MHz}$, $\left.\mathrm{CDCl}_{3}\right): \delta=7.20(\mathrm{~d}, 4 \mathrm{H}), 7.30(\mathrm{t}, 2 \mathrm{H}), 7.43(\mathrm{t}, 4 \mathrm{H})$; ${ }^{13} \mathrm{C}\left\{{ }^{1} \mathrm{H}\right\} \quad\left(100 \mathrm{MHz}, \mathrm{CDCl}_{3}\right): \delta=121.97,126.96$, 129.80, 153.73, 194.94; Anal. Calcd for $\mathrm{C}_{13} \mathrm{H}_{10} \mathrm{O}_{2} \mathrm{~S}$ : C, 67.80; H, 4.38. Found: $\mathrm{C}, 67.66 ; \mathrm{H}, 4.12$. MS (ASAP) $\mathrm{m} / \mathrm{z}$ Calcd for $\mathrm{C}_{15} \mathrm{H}_{14} \mathrm{O}_{2} \mathrm{~S}+\mathrm{H}^{+}$]: 231.05 . Found: 231.05 .

O-(4-chlorophenyl)-O'-(p-tolyl) thiocarbonate $(1 \mathrm{f})$. The crude material $(1.14 \mathrm{~g})$ was recrystallized from acetonitrile to yield $0.954 \mathrm{~g}$ (68\%) of $1 \mathrm{f}$ as white crystals. ${ }^{1} \mathrm{H}$ NMR $(400 \mathrm{MHz}$, $\left.\mathrm{CDCl}_{3}\right): \delta=2.39(\mathrm{~s}, 3 \mathrm{H}), 7.06-7.11(\mathrm{~m}, 2 \mathrm{H}), 7.13-$ $7.19(\mathrm{~m}, 2 \mathrm{H}), 7.22-7.28(\mathrm{~m}, 2 \mathrm{H}), 2.39(\mathrm{~m}, 2 \mathrm{H})$; ${ }^{13} \mathrm{C}\left\{{ }^{1} \mathrm{H}\right\} \quad\left(100 \mathrm{MHz}, \mathrm{CDCl}_{3}\right): \delta=21.14,121.45$, $123.46,129.91,130.37,132.48,136.89$, 151.57, 152.08, 194.90; Anal. Calcd for $\mathrm{C}_{14} \mathrm{H}_{11} \mathrm{O}_{2} \mathrm{SCl}: \mathrm{C}, 60.32 ; \mathrm{H}, 3.98$. Found: $\mathrm{C}, 60.06 ; \mathrm{H}$, 3.68. MS (ASAP) $\mathrm{m} / \mathrm{z}$ Calcd for $\left[\mathrm{C}_{14} \mathrm{H}_{11} \mathrm{O}_{2} \mathrm{SCl}+\mathrm{H}^{+}\right]$: 279.02. Found: 279.02 .

O-(p-tolyl)-O'-(4-(trifluoromethyl)phenyl) thiocarbonate $(1 \mathrm{~g})$. The crude material $(1.26 \mathrm{~g})$ was recrystallized from acetonitrile to yield $0.949 \mathrm{~g}$ $(61 \%)$ of $1 \mathrm{~g}$ as white crystals. ${ }^{1} \mathrm{H}$ NMR $(400 \mathrm{MHz}$, $\left.\mathrm{CDCl}_{3}\right): \delta=2.44(\mathrm{~s}, 3 \mathrm{H}), 7.12-7.17(\mathrm{~m}, 2 \mathrm{H}), 7.27-$ $7.33(\mathrm{~d}, 2 \mathrm{H}), 7.37-7.42(\mathrm{~d}, 2 \mathrm{H}), 7.75-7.80$ (d, $2 \mathrm{H}) ;{ }^{13} \mathrm{C}\left\{{ }^{1} \mathrm{H}\right\}\left(100 \mathrm{MHz}, \mathrm{CDCl}_{3}\right): \delta=21.12,121.41$, 122.77, 123.86, 127.2 (q, J=4 Hz), 129.24 (q, $\mathrm{J}=33 \mathrm{~Hz}), 130.40,136.98,151.52,155.82$, $194.36 ;{ }^{19} \mathrm{~F}\left\{{ }^{1} \mathrm{H}\right\}\left(\mathrm{CDCl}_{3}, 425 \mathrm{MHz}\right): \delta=-61.35(\mathrm{~s}$, 3F); Anal. Calcd for $\mathrm{C}_{15} \mathrm{H}_{11} \mathrm{O}_{2} \mathrm{SF}_{3}: \mathrm{C}, 57.69 ; \mathrm{H}, 3.55$. Found: C, 57.44; H, 3.25. MS (ASAP) $\mathrm{m} / \mathrm{z}$ Calcd for $\left[\mathrm{C}_{15} \mathrm{H}_{11} \mathrm{O}_{2} \mathrm{SF}_{3}+\mathrm{H}^{+}\right]$: 313.05. Found: 313.05.

$O$-cyclohexyl-O'-(p-tolyl) thiocarbonate $(1 \mathrm{~h})$. The crude material was recrystallized from methanol to yield $0.1589 \mathrm{~g}(62 \%)$ of $1 \mathrm{~h}$ as white crystals. ${ }^{1} \mathrm{H}$ NMR $\left(400 \mathrm{MHz}, \mathrm{CDCl}_{3}\right): \delta=1.30-1.53$ $(\mathrm{m}, 3 \mathrm{H}), 1.55-1.75(\mathrm{~m}, 3 \mathrm{H}), 1.76-1.89(\mathrm{~m}, 2 \mathrm{H})$, 2.04-2.17 (m, 2H), $2.4(\mathrm{~s}, 3 \mathrm{H}), 5.28(\mathrm{sep}, 1 \mathrm{H})$, $7.02(\mathrm{~d}, 2 \mathrm{H}), 7.23(\mathrm{~d}, 2 \mathrm{H}) ;{ }^{3} \mathrm{C}\left\{{ }^{1} \mathrm{H}\right\}(100 \mathrm{MHz}$, $\left.\mathrm{CDCl}_{3}\right): \delta=21.13,23.76,25.36,31.01,83.58$, 121.81, 130.14, 136.29, 151.37, 194.72; Anal. Calcd for $\mathrm{C}_{14} \mathrm{H}_{18} \mathrm{O}_{2} \mathrm{~S}: \mathrm{C}, 67.16 ; \mathrm{H}, 7.25$. Found: C, 66.94; $\mathrm{H}, 6$ 6.97. MS (ESCl) $\mathrm{m} / \mathrm{z}$ Calcd for $\left[\mathrm{C}_{14} \mathrm{H}_{18} \mathrm{O}_{2} \mathrm{~S}\right.$ $+\mathrm{Na}^{+}$]: 273.09. Found: 273.09.

$O$-(4-chlorophenyl)-O'-phenyl thiocarbonate $(1 \mathrm{i})$. The crude material $(1.0808 \mathrm{~g})$ was recrystallized from acetonitrile to yield $0.796 \mathrm{~g}$ (60\%) of $1 \mathrm{i}$ as white crystals. 'H NMR (400 MHz,
$\left.\mathrm{CD}_{2} \mathrm{Cl}_{2}\right): \delta=7.2-7.3(\mathrm{~m}, 4 \mathrm{H}), 7.35-7.41(\mathrm{~m} 1 \mathrm{H})$, 7.45-7.54 (m, 4H); ${ }^{13} \mathrm{C}\left\{{ }^{1} \mathrm{H}\right\}\left(100 \mathrm{MHz}, \mathrm{CD}_{2} \mathrm{Cl}_{2}\right): \delta=$ $121.75,123.44,126.9,128.34,129.7,132.25$, 152, 153.63, 195; Anal. Calcd for $\mathrm{C}_{13} \mathrm{H}_{9} \mathrm{O}_{2} \mathrm{SCl}$ : C, 58.98; $\mathrm{H}, 3.43$. Found: $\mathrm{C}, 58.98 ; \mathrm{H}, 3.43$. MS (ASAP) $\mathrm{m} / \mathrm{z}$ Calcd for $\left[\mathrm{C}_{13} \mathrm{H}_{9} \mathrm{O}_{2} \mathrm{SCl}+\mathrm{H}^{+}\right]: 265.01$. Found: 265.01 .

$O$-(2,6-dimethylphenyl-O'-(p-tolyl) thiocarbonate $(1 \mathrm{j})$. The crude material $(1.1751 \mathrm{~g})$ was recrystallized from methanol to yield $0.6015 \mathrm{~g}$ (44\%) of $1 \mathrm{j}$ as white crystals. ' $\mathrm{H}$ NMR $(400 \mathrm{MHz}$, $\left.\mathrm{CD}_{2} \mathrm{Cl}_{2}\right): \delta=2.3(\mathrm{~s}, 6 \mathrm{H}), 2.43(\mathrm{~s}, 3 \mathrm{H}), 7.12(\mathrm{~d}, 2 \mathrm{H})$, $7.16(\mathrm{~s}, 3 \mathrm{H}), 7.31$ (d, 2H); ${ }^{13} \mathrm{C}\left\{{ }^{1} \mathrm{H}\right\} \quad(100 \mathrm{MHz}$, $\left.\mathrm{CD}_{2} \mathrm{Cl}_{2}\right): \delta=15.9,20.7,121.3,126.5,128.8$, 130.1, 130.2, 136.8, 150.8, 151.6, 193.3; Anal. Calcd for $\mathrm{C}_{16} \mathrm{H}_{16} \mathrm{O}_{2} \mathrm{~S}: \mathrm{C}, 70.56 ; \mathrm{H}, 5.92$. Found: $\mathrm{C}$, 70.24; $\mathrm{H}$, 5.71. MS (ASAP) $\mathrm{m} / \mathrm{z}$ Calcd for $\left[\mathrm{C}_{16} \mathrm{H}_{16} \mathrm{O}_{2} \mathrm{~S}+\mathrm{H}^{+}\right]$: 273.09. Found: 273.09.

Thiocarbamate Synthesis. Thiocarbamates are synthesized from a chlorothionoformate and aniline. ${ }^{1} \mathrm{H}$ NMR spectra show broadened lines from slow rotation about the $\mathrm{C}-\mathrm{N}$ amide bond. Therefore, the NMR spectra were recorded at $273 \mathrm{~K}$ where two distinct sets of peaks are observed.

$O$-( $p$-tolyl)- $N$ - $p$-tolyl thiocarbamate (2). $p$ Toluidine $(0.2143 \mathrm{~g}, 2 \mathrm{mmol}$,$) is dissolved in 10 \mathrm{~mL}$ of ethyl acetate and added dropwise to a solution of ethyl acetate $(10 \mathrm{~mL})$ and 0 - $p$-tolyl chlorothionoformate $(1 \mathrm{mmol}, 0.1866 \mathrm{~g})$ cooled to $0{ }^{\circ} \mathrm{C}$ in an ice bath. The mixture was stirred $10 \mathrm{~min}-$ utes, warmed to room temperature and washed with water, saturated brine, and dried over $\mathrm{Na}_{2} \mathrm{SO}_{4}$. After removing the volatiles $1.27 \mathrm{~g}(98 \%)$ of a white powder was collected. The compound is subsequently recrystallized from acetonitrile to yield $0.921 \mathrm{~g}(71 \%)$ of 2 as a white powder. Because thiocarbamates begin to isomerize around $60{ }^{\circ} \mathrm{C}$, it is important not to heat this compound during synthesis or recrystallization. ' $\mathrm{H}$ NMR $(400 \mathrm{MHz}, 273 \mathrm{~K}$, $\left.\mathrm{CD}_{2} \mathrm{Cl}_{2}\right): \delta=2.36+2.39+2.40(\mathrm{~s}, 6 \mathrm{H}), 7.00-7.07$ $(\mathrm{m}, 2 \mathrm{H}), 7.18-7.34(\mathrm{~m}, 5 \mathrm{H}), 7.54(\mathrm{~d}, 1 \mathrm{H}), 8.47+$ $8.83(\mathrm{~s}, 1 \mathrm{H}) ;{ }^{3} \mathrm{C}\left\{{ }^{1} \mathrm{H}\right\}\left(100 \mathrm{MHz}, 273 \mathrm{~K}, \mathrm{CD}_{2} \mathrm{Cl}_{2}\right): \delta=$ 20.7, 20.8, 122.05, 122.08, 122.60, 123.67, $129.46, \quad 129.74, \quad 129.80, \quad 129.83,134.34$, $134.90, \quad 136.02, \quad 136.13,136.55, \quad 150.67$, 151.40, 188.00, 188.12; Anal. Calcd for $\mathrm{C}_{15} \mathrm{H}_{15}$ ONS: $\mathrm{C}, 70.01 ; \mathrm{H}, 5.87$; $\mathrm{N}, 5.44$. Found: C, 69.71; H, 5.79; N, 5.52. MS (ASAP) $\mathrm{m} / \mathrm{z}$ Calcd for $\left.\mathrm{C}_{15} \mathrm{H}_{15} \mathrm{ONS}+\mathrm{H}^{+}\right]:$258.10. Found: 258.10.

\section{$\mathrm{O}$-phenyl- $\mathrm{N}$-methyl(phenyl) thiocarbamate} (3). N-Methylaniline (1.86 g, $1.88 \mathrm{~mL}, 17.37$ $\mathrm{mmol}$ ) is added dropwise to a solution of O-phenyl chlorothionoformate $(8.69 \mathrm{mmol}, 1.5 \mathrm{~g})$ in dichloromethane $(10 \mathrm{~mL})$. The mixture is stirred at 
room temperature for 10 minutes and washed $3 x$ with water and dried over $\mathrm{MgSO}_{4}$. The volatiles are removed under vacuum and the isolated powder recrystallized from ethanol. A white powder is obtained. Yield $1.5544 \mathrm{~g} \mathrm{(74 \% ).} \mathrm{'H} \mathrm{NMR}(400 \mathrm{MHz}$, $\left.273 \mathrm{~K}, \mathrm{CD}_{2} \mathrm{Cl}_{2}\right): \delta=3.69+3.81(\mathrm{~s}, 3 \mathrm{H}), 6.95-7.93$ $(\mathrm{m}, 10 \mathrm{H}) ;{ }^{13} \mathrm{C}\left\{{ }^{1} \mathrm{H}\right\}\left(100 \mathrm{MHz}, 273 \mathrm{~K}, \mathrm{CD}_{2} \mathrm{Cl}_{2}\right): \delta=$ $41,44.8,122.72,123.08,125.84,125.99$, $126.11,127.09,127.8,127.84,129.28,129.3$, $129.51,129.61,143.58,146.27,154,154.13$, 187.78, 189.07; Anal. Calcd for $\mathrm{C}_{14} \mathrm{H}_{13} \mathrm{ONS}$ : C, 69.11; H, 5.38; N, 5.76. Found: C, 68.96; H, 5.14; $\mathrm{N}$, 5.72. MS (ASAP) $\mathrm{m} / \mathrm{z}$ Calcd for $\mathrm{C}_{14} \mathrm{H}_{13} \mathrm{ONS}+\mathrm{H}^{+}$: 244.08. Found: 244.08 .

$N$-methyl- $N, N^{\prime}$-diphenylthiourea (5b). $5 \mathrm{~b}$ is synthesized according to Hendricks et al. ${ }^{3}$ White crystals. Yield $9.321 \mathrm{~g}$ (92\%). ' $\mathrm{H}$ NMR (400 MHz, $\left.\mathrm{CDCl}_{3}\right): \delta=3.69(\mathrm{~s}, 3 \mathrm{H}), 6.93(\mathrm{~b}, 1 \mathrm{H}), 7.14-7.23$ $(\mathrm{m}, 1 \mathrm{H}), 7.28-7.4(\mathrm{~m}, 6 \mathrm{H}), 7.41-7.48(\mathrm{~m}, 1 \mathrm{H})$, 7.52-7.58 $(\mathrm{m}, 2 \mathrm{H}) ;{ }^{13} \mathrm{C}\left\{{ }^{1} \mathrm{H}\right\}\left(100 \mathrm{MHz}, \mathrm{CDCl}_{3}\right): \delta=$ 43.62, 125.71, 126.04, 127.03, 128.63, 128.86, 130.84, 139.30, 143.02, 181.47; Anal. Calcd for $\mathrm{C}_{14} \mathrm{H}_{14} \mathrm{~N}_{2} \mathrm{~S}: \mathrm{C}, 69.39 ; \mathrm{H}, 5.82 ; \mathrm{N}, 11.56$. Found: $\mathrm{C}$, 68.63; H, 5.26; N, 11.41. MS (ASAP) $\mathrm{m} / \mathrm{z}$ Calcd for $\left[\mathrm{C}_{14} \mathrm{H}_{14} \mathrm{~N}_{2} \mathrm{~S}+\mathrm{H}^{+}\right]$: 243.10. Found: 243.10.

Dipyrollidinothione (6b). Pyrrolidine $(5.42 \mathrm{~g}$, $6.26 \mathrm{~mL}, 75 \mathrm{mmol}$ ) is added to a solution of thiocarbonyl diimidazole $(2.67 \mathrm{~g}, 15 \mathrm{mmol})$ in acetonitrile $(75 \mathrm{~mL})$. The solution is stirred at $70{ }^{\circ} \mathrm{C}$ for 16 hours. The volatiles are removed under vacuum, the resultant tan solid is redissolved in dichloromethane $(50 \mathrm{~mL})$ and washed with $30 \mathrm{mmol} \mathrm{HCl}$ dissolved in $20 \mathrm{~mL}$ water, saturated brine, and dried over $\mathrm{Na}_{2} \mathrm{SO}_{4}$. After removing the volatiles, the crude product is recrystallized with hot acetonitrile to yield colorless crystals. Yield: $2.76 \mathrm{~g}(49 \%) .{ }^{1} \mathrm{H}$ NMR $\left(400 \mathrm{MHz}, \mathrm{CDCl}_{3}\right): \delta=1.94-1.84(\mathrm{~m}, 8 \mathrm{H}), 3.65-$ $3.55(\mathrm{~m}, 8 \mathrm{H}) ;{ }^{13} \mathrm{C}\left\{{ }^{1} \mathrm{H}\right\}\left(100 \mathrm{MHz}, \mathrm{CDCl}_{3}\right): \delta=25.84$, 53.08, 184.98; Anal. Calcd for $\mathrm{C}_{9} \mathrm{H}_{16} \mathrm{~N}_{2} \mathrm{~S}$ : C, 58.65; $\mathrm{H}, 8.75$; $\mathrm{N}, 15.20$. Found: $\mathrm{C}, 58.80 ; \mathrm{H}, 8.56$; $\mathrm{N}$, 15.16. MS (ASAP) $\mathrm{m} / \mathrm{z}$ Calcd for $\left[\mathrm{C}_{9} \mathrm{H}_{16} \mathrm{~N}_{2} \mathrm{~S}+\mathrm{H}^{+}\right]$: 185.11. Found: 185.11.

di-p-tolyl carbonate (7). Di-p-tolyl carbonate was synthesized according to a modified literature procedure. ${ }^{36}$ Pyridine $(0.87 \mathrm{~g}, 0.88 \mathrm{~mL}, 11 \mathrm{mmol})$ is added dropwise to a solution of $p$-tolyl chloroformate $(1.79 \mathrm{~g}, 10.5 \mathrm{mmol})$ and $p$-cresol $(1.08 \mathrm{~g}, 10$ $\mathrm{mmol})$ in dichloromethane $(20 \mathrm{~mL})$. The mixture is then heated to reflux for $10 \mathrm{~min}$. The cooled solution is washed with water, sodium hydroxide $(1 \mathrm{M})$, saturated brine, and dried over $\mathrm{Na}_{2} \mathrm{SO}_{4}$. The volatiles are removed under vacuum and the white powder is recrystallized from ethanol to yield 0.643 $\mathrm{g}(25 \%)$ of product. ${ }^{1} \mathrm{H}$ NMR $\left(400 \mathrm{MHz}, \mathrm{CDCl}_{3}\right): \delta=$ $2.39(\mathrm{~s}, 6 \mathrm{H}), 7.17(\mathrm{~d}, 4 \mathrm{H}), 7.22(\mathrm{~d}, 4 \mathrm{H}) ;{ }^{13} \mathrm{C}\left\{{ }^{1} \mathrm{H}\right\}$ $\left(100 \mathrm{MHz}, \mathrm{CDCl}_{3}\right): \delta=20.88,120.6,130,136$, 148.89, 152.46; Anal. Calcd for $\mathrm{C}_{15} \mathrm{H}_{14} \mathrm{O}_{3}$ : C, 74.36; $\mathrm{H}, 5.82$. Found: $\mathrm{C}, 74.54 ; \mathrm{H}, 6.01$. MS (ASAP) $\mathrm{m} / \mathrm{z}$ Calcd for $\mathrm{C}_{15} \mathrm{H}_{14} \mathrm{O}_{3}+\mathrm{H}^{+}$]: 243.10. Found: 243.10.

Thiolcarbonate Synthesis. Compounds $8 \mathrm{a}-8 \mathrm{~b}$ were synthesized following a previously reported procedure. ${ }^{37}$

$0, S$-di-(p-tolyl) thiolcarbonate ( $8 \mathrm{a})$. A solution of $p$-tolyl chloroformate $(3.41 \mathrm{~g}, 20 \mathrm{mmol})$ in $\mathrm{CHCl}_{3}(5 \mathrm{~mL})$ is added dropwise to a solution of 4methyl benzene thiol $(2.48 \mathrm{~g}, 20 \mathrm{mmol})$ and potassium hydroxide $(1.12 \mathrm{~g})$ in $\mathrm{CHCl}_{3}(20 \mathrm{~mL})$ and ethanol $(15 \mathrm{~mL})$. The solution is stirred for 2 hours, filtered, and the volatiles removed under vacuum, yielding a white powder $(4.2682 \mathrm{~g})$ that is subsequently recrystallized from dichloromethane. Yield $2.6077 \mathrm{~g}$ (51\%). ' $\mathrm{H}$ NMR $\left(400 \mathrm{MHz}, \mathrm{CD}_{2} \mathrm{Cl}_{2}\right): \delta=$ $2.34(\mathrm{~s}, 3 \mathrm{H}), 2.39(\mathrm{~s}, 3 \mathrm{H}), 7.01-7.07(\mathrm{~m}, 2 \mathrm{H})$, 7.16-7.21 (m, 2H), 7.22-7.28 (m, $2 \mathrm{H}), 7.45-7.50$ $(\mathrm{m}, 2 \mathrm{H}) ;{ }^{13} \mathrm{C}\left\{{ }^{1} \mathrm{H}\right\} \quad\left(100 \mathrm{MHz}, \mathrm{CD}_{2} \mathrm{Cl}_{2}\right): \delta=20.53$, 21.02, 120.88, 123.71, 129.93, 130.04, 134.86, 136.15, 140.51, 149.14, 169.14; Anal. Calcd for $\mathrm{C}_{15} \mathrm{H}_{14} \mathrm{O}_{2} \mathrm{~S}: \mathrm{C}, 69.74 ; \mathrm{H}, 5.46$. Found: $\mathrm{C}, 69.53 ; \mathrm{H}$, 5.18. MS (ASAP) $\mathrm{m} / \mathrm{z}$ Calcd for $\mathrm{C}_{15} \mathrm{H}_{14} \mathrm{O}_{2} \mathrm{~S}+\mathrm{H}^{+}$]: 259.08. Found: 259.08 .

$0, S$-di-(phenyl) thiolcarbonate ( $8 \mathrm{~b})$. White crystals. Yield $1.947 \mathrm{~g} \mathrm{(42 \% ).}{ }^{1} \mathrm{H}$ NMR $(400 \mathrm{MHz}$, $\left.\mathrm{CD}_{2} \mathrm{Cl}_{2}\right): \delta=7.15-7.21(\mathrm{~m}, 2 \mathrm{H}), 7.24-7.30(\mathrm{~m}, 1 \mathrm{H})$, 7.36-7.50 (m, 5H), 7.59-7.65 (m, 2H); ${ }^{13} \mathrm{C}\left\{{ }^{1} \mathrm{H}\right\}$ $\left(101 \mathrm{MHz}, \mathrm{CD}_{2} \mathrm{Cl}_{2}\right): \delta=121.64,126.68,127.63$, $129.71, \quad 129.93,130.34,135.31,151.72$, 169.08; Anal. Calcd for $\mathrm{C}_{13} \mathrm{H}_{10} \mathrm{O}_{2} \mathrm{~S}$ : C, 67.80; $\mathrm{H}$, 4.38. Found: $\mathrm{C}, 67.53 ; \mathrm{H}, 4.20$. MS (ASAP) $\mathrm{m} / \mathrm{z}$ Calcd for $\mathrm{C}_{13} \mathrm{H}_{10} \mathrm{O}_{2} \mathrm{~S}+\mathrm{H}^{+}$]: 231.05 . Found: 231.05 .

p-Tolyl oleate (9a). Pyridine $(0.475 \mathrm{~g}, 0.484$ $\mathrm{mL}, 6 \mathrm{mmol})$ is added dropwise to a solution of oleoyl chloride $(1.50 \mathrm{~g}, 5 \mathrm{mmol})$ and $p$-cresol $(0.52$ $\mathrm{g}, 4.8 \mathrm{mmol})$ in $\mathrm{CH}_{2} \mathrm{Cl}_{2}(20 \mathrm{~mL})$. The mixture is heated to reflux for $10 \mathrm{~min}$ and subsequently washed with water, $\mathrm{NaOH}(1 \mathrm{M})$, saturated brine, and dried over $\mathrm{Na}_{2} \mathrm{SO}_{4}$ to yield $1.44 \mathrm{~g}(81 \%)$ of a brown oil. ' $\mathrm{H}$ NMR $\left(400 \mathrm{MHz}, \mathrm{CDCl}_{3}\right): \delta=0.92(\mathrm{t}$, $3 \mathrm{H}$ ), 1.17-1.51 (m, 20H), 1.78 (quin, 2H), 1.97$2.14(\mathrm{~m}, 4 \mathrm{H}), 2.37(\mathrm{~s}, 3 \mathrm{H}), 2.56(\mathrm{t}, 2 \mathrm{H}), 5.38(\mathrm{~m}$, $2 \mathrm{H}), 6.98(\mathrm{~d}, 2 \mathrm{H}), 7.19(\mathrm{~d}, 2 \mathrm{H}) ;{ }^{13} \mathrm{C}\left\{{ }^{1} \mathrm{H}\right\}(100 \mathrm{MHz}$, $\left.\mathrm{CDCl}_{3}\right): \delta=14.22,20.88,22.77,25.02,27.23$, 27.3, 29.16, 29.24, 29.41, 29.62, 29.76, 29.85, 32, 34.4, 121.1, 129.74, 129.88, 130.04, 135.2, 148.65, 172.37; Anal. Calcd for $\mathrm{C}_{25} \mathrm{H}_{40} \mathrm{O}_{2}$ : C, 80.59; $\mathrm{H}, 10.82$. Found: $\mathrm{C}, 80.31 ; \mathrm{H}, 10.54$. MS (ASAP) $\mathrm{m} / \mathrm{z}$ Calcd for $\left.\mathrm{C}_{25} \mathrm{H}_{40} \mathrm{O}_{2}+\mathrm{H}^{+}\right]$: 373.31. Found: 373.31 . 
Phenyl oleate (9b). Brown oil. Yield $1.153 \mathrm{~g}$ (67\%). ${ }^{1} \mathrm{H}$ NMR $\left(400 \mathrm{MHz}, \mathrm{CD}_{2} \mathrm{Cl}_{2}\right): \delta=0.89(\mathrm{t}$, $3 \mathrm{H}$ ), 1.20-1.49 (m, 2OH), 1.74 (quin, $2 \mathrm{H}$ ), 1.97$2.10(\mathrm{~m}, 4 \mathrm{H}), 2.54(\mathrm{t}, 2 \mathrm{H}), 5.36(\mathrm{~m}, 2 \mathrm{H}), 7.03-$ $7.09(\mathrm{~m}, 2 \mathrm{H}), 7.19-7.26(\mathrm{~m}, 1 \mathrm{H}), 7.35-7.41(\mathrm{~m}$, $2 \mathrm{H}) ;{ }^{13} \mathrm{C}\left\{{ }^{1} \mathrm{H}\right\}\left(101 \mathrm{MHz}, \mathrm{CD}_{2} \mathrm{Cl}_{2}\right): \delta=14.32,23.13$, 25.32, 27.57, 27.61, 29.49, 29.54, 29.60, 29.76, $29.95,30.14,30.22,32.35,34.69, \quad 122.10$, 126.06, 129.74, 130.13, 130.36, 151.35, 172.67; Anal. Calcd for $\mathrm{C}_{24} \mathrm{H}_{38} \mathrm{O}_{2}$ : C, 80.39; $\mathrm{H}$, 10.68. Found: $\mathrm{C}, 79.82 ; \mathrm{H}, 11.27$. MS (ASAP) $\mathrm{m} / \mathrm{z}$ Calcd for $\mathrm{C}_{24} \mathrm{H}_{38} \mathrm{O}_{2}+\mathrm{H}^{+}$]: 359.30. Found: 359.29.

Synthesis of CdS nanocrystals. In a nitrogenfilled glove box, a three neck round bottom flask is loaded with cadmium oleate $(0.18 \mathrm{mmol}, 0.122 \mathrm{~g})$, octadecene (14.25 mL, $11.2 \mathrm{~g}, 44.4 \mathrm{mmol})$, and oleic acid $(0.102 \mathrm{~g}, 0.114 \mathrm{~mL}, 0.36 \mathrm{mmol}$,$) . A 4 \mathrm{~mL}$ vial was filled with the desired sulfur precursor $(0.15 \mathrm{mmol})$ and diphenyl ether $(0.75 \mathrm{~mL}, 0.75 \mathrm{~g})$. The three neck round bottom flask is transferred to a Schlenk line and heated to $240{ }^{\circ} \mathrm{C}$ under Ar. The sulfur precursor solution is then injected into the cadmium oleate solution and left to react for the appropriate time. The resulting nanocrystals were isolated from the reaction mixture by precipitation with acetone and centrifugation. The yellow residue is redispersed in hexane $(10 \mathrm{~mL})$ and acetone $(5-$ $10 \mathrm{~mL}$ ) is added in $0.5 \mathrm{~mL}$ portions to precipitate cadmium oleate, without precipitating the nanocrystals. This solution was centrifuged. The supernatant was collected and the nanocrystals precipitated with the addition of $25 \mathrm{~mL}$ of acetone. The nanocrystals were washed three additional times with toluene/methyl acetate.

Nanocrystal Formation Kinetics. Quantitative aliquots of approximately $0.1 \mathrm{~mL}$ were taken from a CdS nanocrystal reaction and deposited into a previously weighed vial. A mass of toluene equal to $2.5 \mathrm{x}$ the weight of the aliquot was added to the vial to standardize aliquot concentration. UV-vis absorption spectra were taken of each aliquot and the concentration of $\mathrm{CdS}$ in the aliquot was calculated from the size dependent extinction coefficient at the first excitonic absorption maximum using Eq. 1. ${ }^{17}$ Using a second method, the absorbance at 300 $\mathrm{nm}$ was monitored as a proxy for CdS conversion. This second method was used to assess the validity of our proposed correction to the size dependent extinction coefficient for CdS. The kinetics collected from each method was fit to a first order fit whose rate constant is reported in Figure 2.

Cadmium Sulfide Reaction Yield Determination. A $2 x$ reaction scaleup was performed in a 3 neck round bottom flask connected to a distillation head. At the end of the reaction, octadecene was distilled from the reaction solution and the concentrated nanoparticle solution was purified using the procedure described above. The mass of the dried nanocrystals was measured and the sample was dispersed in $\mathrm{CDCl}_{3}$ containing dimethyl terepthalate in known concentration. By integrating the dimethyl terepthalate and alkene signal of cadmium oleate, the concentration of cadmium oleate ligands could be determined. From the oleate concentration and the mass of the nanocrystals used to make the NMR sample, the mass of cadmium sulfide could be calculated by assuming the empirical formula: $(\mathrm{CdS})_{\mathrm{n}}\left(\left(\mathrm{Cd}\left(\mathrm{O}_{2} \mathrm{CR}\right)_{2}\right)_{\mathrm{m}}\right.$.

Thiocarbonate Reaction Coproduct Identification. In a nitrogen-filled glove box, a three neck round bottom flask is loaded with cadmium oleate $(0.18 \mathrm{mmol}, 0.122 \mathrm{~g})$, octadecene (14.25 $\mathrm{mL}, 11.2 \mathrm{~g}, 44.4 \mathrm{mmol})$, and oleic acid $(0.102 \mathrm{~g}$, $0.114 \mathrm{~mL}, 0.36 \mathrm{mmol}$, ). A $4 \mathrm{~mL}$ vial was filled with the desired sulfur precursor $1 \mathrm{c}$ or $1 \mathrm{e}(0.15 \mathrm{mmol})$ and tetraglyme $(0.75 \mathrm{~mL}, 0.75 \mathrm{~g})$. The three neck round bottom flask is transferred to a Schlenk line and heated to $240{ }^{\circ} \mathrm{C}$ under Ar. The sulfur precursor solution is then injected into the cadmium oleate solution and left to react for the appropriate time. $200 \mu \mathrm{L}$ aliquots of the reaction solution are dissolved in $200 \mu \mathrm{L}$ of $\mathrm{CD}_{2} \mathrm{Cl}_{2}$ and $100 \mu \mathrm{L}$ of a 22.4 $\mathrm{mM}$ solution of dimethyl terepthalate dissolved in $\mathrm{CD}_{2} \mathrm{Cl}_{2}$. ${ }^{1} \mathrm{H}$ NMR spectra were collected with a relaxation delay time of 30 seconds. Independently synthesized samples of coproducts were spiked into the NMR tubes to verify their identities.

Coproduct Reaction Determination. Octadecene $(14.25 \mathrm{~mL})$, tetraglyme $(0.75 \mathrm{~mL})$, and 7 $(0.0363 \mathrm{~g}, 0.15 \mathrm{mmol}$,$) or p$-cresol $(0.0162 \mathrm{~g}$, $0.15 \mathrm{mmol})$ and oleic acid $(0.102 \mathrm{~g}, 0.36 \mathrm{mmol})$ or oleic anhydride $(0.082 \mathrm{~g}, 0.15 \mathrm{mmol})$ were combined in a 3 neck round bottom flask. The solution was degassed on a schlenk line for 10 minutes and heated to $240{ }^{\circ} \mathrm{C}$. A starting aliquot was taken as soon as the precursors became soluble, and time was started as soon as the solution temperature hit $240{ }^{\circ} \mathrm{C}$. $200 \mu \mathrm{L}$ reaction aliquots were dispersed in $\mathrm{CD}_{2} \mathrm{Cl}_{2}$ for subsequent ${ }^{1} \mathrm{H}$ NMR studies. ${ }^{1} \mathrm{H}$ NMR data is plotted with an estimated $10 \%$ error inherent to the technique.

\section{ASSOCIATED CONTENT}

\section{Supporting Information}

The Supporting Information is available free of charge on the ACS Publications website. 
Additional nanocrystal synthesis and precursor coproduct identification Figures S1-S23 and ${ }^{1} \mathrm{H},{ }^{13} \mathrm{C}\left\{{ }^{1} \mathrm{H}\right\}$, and ${ }^{19} \mathrm{~F}\left\{{ }^{1} \mathrm{H}\right\}$ NMR characterization of molecules. (PDF)

\section{AUTHOR INFORMATION}

\section{Corresponding Author}

* jso2115@columbia.edu

\section{ACKNOWLEDGEMENT}

This work was supported by the US Army Research Laboratory and the US Army Research Office under contract number W911NF-12-1-0594 (MURI). Some of this work was performed at the Simons Electron Microscopy Center and National Resource for Automated Molecular Microscopy located at the New York Structural Biology Center, supported by grants from the Simons Foundation (349247), NYSTAR, and the NIH National Institute of General Medical Sciences (GM103310). We would like to acknowledge Columbia University's Nanoscience Initiative for the use of its shared facilities, and the Fu Foundation School of Engineering and Applied Science and the Faculty of Arts \& Sciences for their support of the CNI Facilities. JRD acknowledges the Belgian American Education Foundation (B.A.E.F.) and Fullbright for sponsorship of his research stay at Columbia University. The authors acknowledge Michael P. Campos for helpful discussions and assistance collecting powder x-ray diffraction data. The authors would like to acknowledge Mark P. Hendricks, Isabel Billinge, and Victor Gordillo for helpful discussions.

\section{REFERENCES}

1. Owen, J. S.; Chan, E. M.; Liu, H.; Alivisatos, A. P. Precursor Conversion Kinetics and the Nucleation of Cadmium Selenide Nanocrystals. J. Am. Chem. Soc. 2010, 132, 18206-18213.

2. Garcia-Rodriguez, R.; Hendricks, M. P.; Cossairt, B. M.; Liu, H.; Owen, J. S. Conversion Reactions of Cadmium Chalcogenide Nanocrystal Precursors. Chem. Mater. 2013, 25, 1233-1249.

3. Hendricks, M. P.; Campos, M. P.; Cleveland, G. T.; JenLa Plante, I.; Owen, J. S. A Tunable Library of Substituted Thiourea Precursors to Metal Sulfide Nanocrystals. Science 2015, 348, 1226-1230.

4. Campos, M. P.; Hendricks, M. P.; Beecher, A. N.; Walravens, W.; Swain, R. A.; Cleveland, G. T.; Hens, Z.; Sfeir, M. Y.; Owen, J. S. A Library of Selenourea Precursors to PbSe Nanocrystals with Size Distributions near the Homogeneous Limit. J. Am. Chem. Soc. 2017, 139, 22962305.

5. Guo, Y.; Alvarado, S. R.; Barclay, J. D.; Vela, J. ShapeProgrammed Nanofabrication: Understanding the Reactivity of Dichalcogenide Precursors. ACS Nano 2013, 7, 3616-3626.
6. Ruberu, T. P. A.; Albright, H. R.; Callis, B.; Ward, B.; Cisneros, J.; Fan, H.; Vela, J. Molecular Control of the Nanoscale: Effect of Phosphine-Chalcogenide Reactivity on CdS-CdSe Nanocrystal Composition and Morphology. ACS Nano 2012, 6, 5348-5359.

7. Hens, Z. Economical Routes to Colloidal Nanocrystals. Science 2015, 348, 1211-1212.

8. Harris, D. K.; Bawendi, M. G. Improved Precursor Chemistry for the Synthesis of III-V Quantum Dots. J. Am. Chem. Soc. 2012, 134, 20211-20213.

9. Joung, S.; Yoon, S.; Han, C. S.; Kim, Y.; Jeong, S. Facile Synthesis of Uniform Large-Sized InP Nanocrystal Quantum Dots Using Tris(tertbutyldimethylsilyl)phosphine. Nanoscale Res. Lett. 2012 , 7, 93.

10. Gary, D. C.; Glassy, B. A.; Cossairt, B. M. Investigation of Indium Phosphide Quantum Dot Nucleation and Growth Utilizing Triarylsilylphosphine Precursors. Chem. Mater. 2014, 26, 1734-1744.

11. Murray, C. B.; Norris, D. J.; Bawendi, M. G. Synthesis and Characterization of Nearly Monodisperse CdE (E = Sulfur, Selenium, Tellurium) Semiconductor Nanocrystallites. J. Am. Chem. Soc. 1993, 115, 8706-8715.

12. Peng, Z. A.; Peng, X. Formation of High-Quality $\mathrm{CdTe}, \mathrm{CdSe}$, and CdS Nanocrystals Using $\mathrm{CdO}$ as Precursor. J. Am. Chem. Soc. 2001, 123, 183-184.

13. Cao, Y. C.; Wang, J. One-Pot Synthesis of HighQuality Zinc-Blende CdS Nanocrystals. J. Am. Chem. Soc. 2004, 126, 14336-14337.

14. Ouyang, J.; Kuijper, J.; Brot, S.; Kingston, D.; Wu, X.; Leek, D. M.; Hu, M. Z.; Ripmeester, J. A.; Yu, K. Photoluminescent Colloidal CdS Nanocrystals with High Quality via Noninjection One-Pot Synthesis in 1-Octadecene. J. Phys. Chem. C 2009, 113, 7579-7593.

15. Al-Kazimi, H. R.; Tarbell, D. S.; Plant, D. A Study of the Schönberg Rearrangement of Diaryl Thioncarbonates to Diaryl Thiolcarbonates J. Am. Chem. Soc. 1955, 77, 2479-2482.

16. Goßen, L.; Döhring, A. Lewis Acids as Highly Efficient Catalysts for the Decarboxylative Esterification of Carboxylic Acids with Dialkyl Dicarbonates. Adv. Synth. Cat. 2003, 345, 943-947.

17. Yu, W. W.; Qu, L.; Guo, W.; Peng, X. Experimental Determination of the Extinction Coefficient of CdTe, CdSe, and CdS Nanocrystals. Chem. Mater. 2003, 15, 2854-2860.

18. Jasieniak, J.; Smith, L.; van Embden, J.; Mulvaney, P. Re-examination of the Size-Dependent Absorption Properties of CdSe Quantum Dots. J. Phys. Chem. C 2009, 113, 19468-19474.

19. Liu, H.; Owen, J. S.; Alivisatos, A. P. Mechanistic Study of Precursor Evolution in Colloidal Group II-VI Semiconductor Nanocrystal Synthesis. J. Am. Chem. Soc. 2007, 129, 305-312.

20. Sugimoto, T.; Shiba, F.; Sekiguchi, T.; Itoh, H. Spontaneous Nucleation of Monodisperse Silver Halide Particles from Homogeneous Gelatin Solution I: Silver Chloride. Colloids Surf. A Physicochem. Eng. Asp. 2000, 164, 183203.

21. Sugimoto, T.; Shiba, F. Spontaneous Nucleation of Monodisperse Silver Halide Particles from Homogeneous 
Gelatin Solution II: Silver Bromide. Colloids Surf. A Physicochem. Eng. Asp. 2000, 164, 205-215.

22. Abe, S.; Capek, R. K.; De Geyter, B.; Hens, Z. Tuning the Postfocused Size of Colloidal Nanocrystals by the Reaction Rate: From Theory to Application. ACS Nano 2012, 6, 42-53.

23. Zonta, C.; De Lucchi, O.; Volpicelli, R.; Cotarca, L. Thione-Thiol Rearrangement: Miyazaki-Newman-Kwart Rearrangement and Others. Top Curr. Chem. 2007, 275, 131-161.

24. Schönberg, A.; Varga, L. Über die (Thermische) Umlagerung von Thion-Kohlensäure-Estern in ThiolKohlensäure-Ester. (16. Mitteil. über Organische Schwefelverbindungen.) Ber. Dtsch. Chem. Ges. 1930, 63, 178.

25. Newman, M. S.; Karnes, H. A. The Conversion of Phenols to Thiophenols via Dialkylthiocarbamates. J. Org. Chem. 1966, 31, 3980.

26. Kwart, H.; Evans, E. R. The Vapor Phase Rearrangement of Thioncarbonates and Thiocarbamates. J. Org. Chem. 1966, 31, 410.

27. Weidman, M. C.; Beck, M. E.; Hoffman, R. S.; Prins, F.; Tisdale, W. A. Monodisperse, Air-Stable PbS Nanocrystals via Precursor Stoichiometry Control. ACS Nano 2014, 8, 6363-6371.

28. Cui, J.; Beyler, A. P.; Marshall, L. F.; Chen, O.; Harris, D. K.; Wanger, D. D.; Brokmann, X.; Bawendi, M. G. Direct Probe of Spectral Inhomogeneity Reveals Synthetic Tunability of Single-Nanocrystal Spectral Linewidths. Nat. Chem. 2013, 5, 602-606.

29. Chen, O.; Zhao, J.; Chauhan, V. P.; Cui, J.; Wong, C.; Harris, D. K.; Wei, H.; Han, H.; Fukumura, D.; Jain, R. K.; Bawendi, M. G. Compact High-Quality CdSe-CdS Core-Shell Nanocrystals with Narrow Emission Linewidths and Suppressed Blinking. Nat. Mat. 2013, 12, 445-451.

30. Cui, J.; Beyler, A. P.; Coropceanu, I.; Cleary, L.; Avila, T. R.; Chen, Y.; Cordero, J. M.; Heathcote, S. L.; Harris, D. K.; Chen, O.; Cao, J.; Bawendi, M. G. Evolution of the Single-Nanocrystal Photoluminescence Linewidth with Size and Shell: Implications for Exciton-Phonon Coupling and the Optimization of Spectral Linewidths. Nano Lett. 2016, 16, 289-296.

31. Busby, E.; Anderson, N. C.; Owen, J. S.; Sfeir, M. Y. Effect of Surface Stoichiometry on Blinking and Hole Trapping Dynamics in CdSe Nanocrystals. J. Phys. Chem. C. 2015, 119, 27797-27803.

32. We tested the hypothesis that thiocarbonate coproducts are responsible and found no change to the FWHM of the reaction of tetramethyl thiourea (6a) with cadmium oleate in the presence of $0, O^{\prime}$-di-p-tolyl carbonate (7) (Figure S22).

33. Anderson, N. C.; Hendricks, M. P.; Choi J. J.; Owen, J. S. Ligand Exchange and the Stoichiometry of Metal Chalcogenide Nanocrystals: Spectroscopic Observation of Facile Metal-Carboxylate Displacement and Binding. J. Am. Chem. Soc. 2013, 135, 18536-185-48.

34. Yang, Y. A.; Wu, H.; Williams, K. R.; Cao, Y. C. Synthesis of CdSe and CdTe Nanocrystals without Precursor Injection. Angew. Chem. Int. Ed. 2005, 44, 6712-6715.
35. Millan, D. S.; Prager, R. H. The Dealkylation of Tertiary Aliphatic Amines with Phenyl Chlorothionoformate. Tet. Lett. 1998, 39, 4387-4390.

36. Rahmathullah, S. M.; Hall, J. E.; Bender, B. C.; McCurdy, D. R.; Tidwell, R. R.; Boykin, D. W. Prodrugs for Amidines: Synthesis and Anti-Pneumocystis carinii Activity of Carbamates of 2,5-Bis(4-amidinophenyl)furan. J. Med. Chem. 1999, 42, 3994-4000.

37. Creighton, A. M.; Owen, L. N.; White, G. R. Cytotoxic Compounds. Part III. Some Derivatives of $p-(N N-$ di-2chloroethyl- and $p,-(N N-d i-2-b r o m o e t h y l-$ amino)thiophenol. J. Chem. Soc. 1961, 2375-2381. 


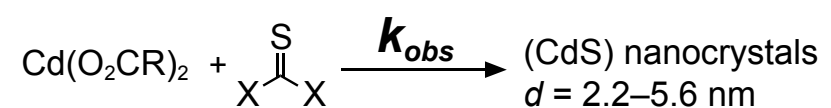

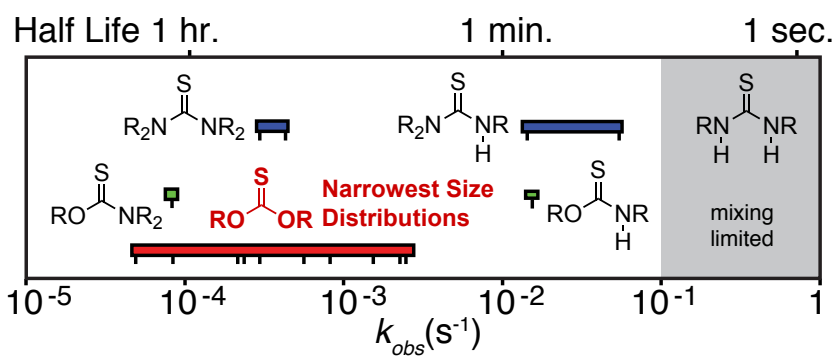

